\title{
Elasticity of Demand a Critical Form Tourism Market Position: Understanding Zimbabwe Tourism Destination
}

\author{
Farai Chigora (Corresponding author) \\ MBA, BCom (hons) Tourism and Hospitality Management, Doctorate in Business \\ Administration candidate with University of KwaZulu-Natal, Graduate School of Business \\ and Leadership, Westville Campus, South Africa. Lecturer in the faculty of commerce with \\ Catholic University of Zimbabwe \\ E-mail: fchigora@yahoo.com Tel: 263-772-886-871
}

\author{
Clever Vutete \\ MBA, MSc in Marketing Management, BCom Marketing Management, Lecturer, \\ ZOU-Harare Region \\ E-mail: vusabhuku@gmail.com Tel: 263-772-458-026
}

Received: August 19, 2015 Accepted: October 9, 2015 Published: November 13, 2015

doi:10.5296/csbm.v2i2.8570 URL: http://dx.doi.org/10.5296/csbm.v2i2.8570

\begin{abstract}
The study investigated the concept of elasticity of demand in relation to Zimbabwe tourism destination performance. The main variables for analysis as drivers for elasticity of demand in Zimbabwe tourism destination have been identified as price charged, tourists' disposable income, price of other related tourism destinations, marketing and media publicity. The study applied a triangulation research design (both quantitative and qualitative designs). The results of the research showed that price, disposable income and price of other related tourism destinations are critical in enhancing market position of the Zimbabwe tourism destination. Also tourism specified variables which are naturalistic and cultural originality have proved to be on the forefront in improving tourism demand. This is because they are tools which enhance decision making, pricing strategy, government tax levels and price discrimination. The research therefore recommended a low pricing strategy to meet the general economic affordability, aligning to the low disposable income of the locals and matching with the prices charged by other regional and international destinations so as to be competitive and
\end{abstract}




\section{Macrothink}

Case Studies in Business and Management

ISSN 2333-3324

2015, Vol. 2, No. 2

gain market share. Original culture and sustainable management of natural resources have been regarded as pertinent drivers to improve tourism demand in Zimbabwe.

Keywords: elasticity, tourism, market position, Zimbabwe, destination 


\section{Introduction}

Elasticity of demand has been established as a responsiveness of quantity demanded due to changes in the price and other determinants of demand (Lipsey, 2009). Tourism destinations like general products depend on the responsiveness of tourists in meeting changes in prices and other determinants. Globally, tourism demand has followed changes in various factors such as changes in income levels and competition between destinations in the form of substitutes. The concept of elasticity of demand has been identified as a combination of the function of own price, disposable income and price of other related goods. This has resulted in three main types of elasticity of demand namely own price elasticity of demand, income elasticity of demand and cross price elasticity of demand (Sloman, 2003). Own price elasticity of demand refers to the measurement of the responsiveness of quantity demanded due to a change in the price of the same product or service at a given period in time (Mankiw \& Taylor, 2006). In relation to tourism destinations own price elasticity can be regarded as the responsiveness of tourists demand for tourism offerings due to a change in the prices charged by tourism businesses. The income elasticity of demand is the responsiveness of quantity demanded for a service or product in relation to a change in the disposable income of the customers (Samuelson \& Nordhaus, 2005). The disposable income of tourists can affect the demand for tourism products and services. Cross price elasticity of demand is therefore a measurement of the responsiveness of quantity demanded due to a change in the price of related goods and services (Lipsey, 2009). The related goods might be complements or substitutes. In relation to tourism destinations, cross price elasticity can be referred to as a measure of how tourists demand tourism products and service in a destination in relation to the price being charged by other destinations on the global market. The Zimbabwe tourism destination has experienced slumps in touristic businesses over the years especially the periods after year 2000. The reasons for the downfalls have been pointed to unfavorable social, economic and political issues (Chibaya, 2013). The effect of these uncertainties has seen tourism businesses closing and the tourism sector failing to achieve its mandate as a strengthening pillar of the Zimbabwean economy. Prices have increased tremendously with massive salary cuts and retrenchments. Also other destinations especially those in the African region have gained an upper hand in their pricing becoming close substitutes for Zimbabwe as a tourism destination. Therefore this has created a need to investigate how the knowledge of elasticity of demand can improve operations of tourism businesses in Zimbabwe.

\section{Statement of Problem}

Various factors have been considered as determinants for the falling down of Zimbabwe tourism destination performance. The generalization of the variables deters a common understanding of the real market variables that should work on to improve the status quo. The study engaged an elasticity of demand analysis so as to determine on the factors that are most critical to which the tourism industry in the country respond to their changes.

\section{Literature Review}

The significance of the concept of tourism elasticity of demand differs from one destination to another globally (Crouch, 1995). This is because of variety and uniqueness in tourism 
offerings from one destination to another. Price has been a common factor in determining responses of tourists ranging between elastic and inelastic with the most "wanderlust" destinations having an inelastic demand and "sun lust" carrying an elastic demand (Crouch, 1994a). Inelastic demand meaning that a more than proportional increase in price leads to a less than proportional decrease in the quantity demanded for tourism activities (Manki \& Taylor, 2006). Those destinations with an elastic demand, when there is a less than proportional increase in the price it results in a more than proportional decrease in the quantity demanded for its offerings. Song et al. (2010) tested the demand elasticity using a bias-corrected bootstrap and found out that the demand for long-haul and improving economies is highly elastic to income meaning that the more the income received, the more people want to make tourism visits and the short-haul destinations are highly price elastic such that the less expensive the more tourists and the high expensive the less tourists. Elasticity of demand is changes following trends in price and income (Tran, 2011). Also, the consumer theory denotes that there is a strong effect on the international tourism arising from changes in the price of complements and substitutes (Muchapondwa \& Pimhidzai, 2011). These complements and substitutes can be regarded as resultant variables of cross elasticity of demand (Divisekera, 2003). Lim, Min and McAleer (2008) analysis of the income elasticity of demand in New Zealand showed that Japanese tourists have appreciated spending in the country's tourism. Also Croes and Vanegas (2005) investigated elasticity in the US, Netherlands, and Venezuela and found out that Venezuelan tourists are more elastic to price than the American and the Dutch tourists.

\section{Methodology}

The study was based on a triangulation research design which is a combination of both quantitative and qualitative approaches. The respondents to the study included 15 from hotels, 5 from ministry of tourism and hospitality, 4 from ministry of finance and economic development, 17 travel agents, 7 holiday resorts and 6 from Zimbabwe Tourism Authority making up a total population of 54. A qualitative research was done in order to obtain elasticity variables common in the Zimbabwe tourism industry. In-depth interview guide was used as qualitative research instrument. Various top operation managers and tourism consultancy were interviewed. The questionnaire as a quantitative research instrument helped in obtaining data on the elasticity variables affecting Zimbabwe tourism market performance. Data analysis was done using average means ranging from 1 to 5 (1= Strongly Agree) (5=Strongly Disagree) and these were presented in the form of a table and bar graph.

\section{Findings and Discussions}

The study used a qualitative approach in determining the most crucial variables that affects elasticity of demand in the Zimbabwe tourism destination. This was through in-depth interviews that were done to operation managers and consultancy in the tourism industry. The determinants were further analysed on their effect to various respondents using a survey questionnaire as a quantitative research design and the results are as shown in table 1 and figure 1 below. 
Table 1. Responses on the variables affecting elasticity of demand in Zimbabwe tourism destination

\begin{tabular}{|l|l|l|l|l|l|}
\hline Respondents & $\begin{array}{l}\text { Change in } \\
\text { Prices }\end{array}$ & $\begin{array}{l}\text { Change in } \\
\text { Disposable } \\
\text { Income }\end{array}$ & $\begin{array}{l}\text { Change price of } \\
\text { other } \\
\text { destinations }\end{array}$ & $\begin{array}{l}\text { Failing to } \\
\text { market }\end{array}$ & $\begin{array}{l}\text { Negative media } \\
\text { publicity }\end{array}$ \\
\hline Hotels & 2.141 & 1.001 & 1.220 & 2.789 & 1.210 \\
\hline $\begin{array}{l}\text { Ministry of } \\
\text { Tourism and } \\
\text { hospitality }\end{array}$ & 1.988 & 1.108 & 1.117 & 3.456 & 1.012 \\
\hline $\begin{array}{l}\text { Ministry of } \\
\text { Finance and } \\
\text { Economic } \\
\text { Development }\end{array}$ & 1.121 & 1.056 & 2.971 & 2.777 & 1.359 \\
\hline Travel agents & 2.101 & 1.410 & 1.003 & 2.547 & 1.122 \\
\hline Holiday resorts & 1.531 & 1.007 & 1.210 & 3.561 & 1.050 \\
\hline $\begin{array}{l}\text { Zimbabwe } \\
\text { Tourism } \\
\text { Authority }\end{array}$ & 1.314 & 1.112 & 1.064 & 4.556 & 1.001 \\
\hline Total means & $\mathbf{1 0 . 1 9 6}$ & $\mathbf{6 . 6 9 4}$ & $\mathbf{8 . 5 8 5}$ & $\mathbf{1 9 . 6 8 6}$ & $\mathbf{6 7 5 4}$ \\
\hline Average means & $\mathbf{1 . 6 9 9}$ & $\mathbf{1 . 1 1 5}$ & $\mathbf{1 . 4 3 1}$ & $\mathbf{3 . 2 8 1}$ & $\mathbf{1 . 1 2 6}$ \\
\hline
\end{tabular}

Note. The average mean are in a range of 1-5 (1= Strongly Agree; 5=Strongly Disagree).

Source: Research Survey (2015).

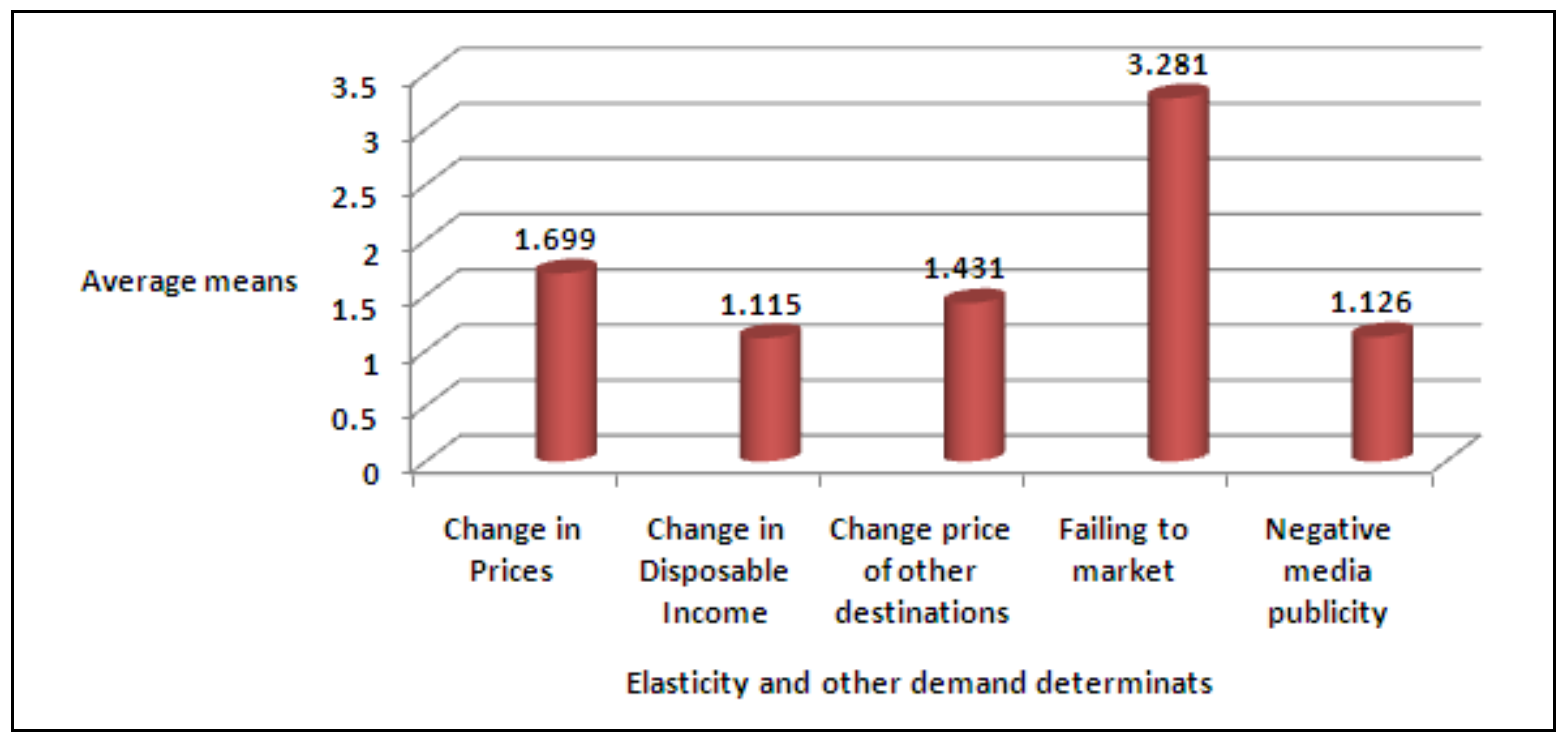

Figure 1. Responses on the variables affecting elasticity of demand in Zimbabwe tourism destination

Note. The average mean are in a range of 1-5 (1= Strongly Agree; 5=Strongly Disagree).

Source: Research Survey (2015). 
The average means in table 1 and figure 1 above shows that changes in disposable income has the lowest average mean (1.115) followed by negative media publicity (1.126), changes in the price of other destinations (1.431) and changes in price (1.699). Failing to market has a high average mean of 3.281. Disposable income can be referred to as net income after tax. The Zimbabwe tourism destination is struggling to provide wages and salaries that meet the poverty datum level. This has negatively affected the consumption of tourism products and services by local people. Also at an international level various economies both developed and developing countries have faced economic slumps over the years leading to retrenchments and high unemployment rates. This has reduced the aggregate disposable income levels at a global level. The tourism consumption has been reduced therefore showing that levels of incomes affect the budget of both local and foreign tourists. The responsiveness of tourism demand to negative media publicity is also highly negative. This is because information and word of mouth has a greater effect in tourist consumption behaviour. Zimbabwe tourism destination has been tarnished by international negative media publicity which resulted in reduced demand for tourism offerings. Other existing tourism destinations especially in the Southern African region have become substitutes for Zimbabwe tourism destination over the years. This is because the shortages and inflationary gaps that transpired in the country resulted in the prices charged in Zimbabwe tourism destination becoming relatively high thus losing market share to other destinations. The general price level of tourism products and services also affected the elasticity of demand but not to an extent of other issues like income levels and media publicity. Zimbabwe Tourism Authority has aggressively marketed the tourism destination over the years and this is shown by the response of participant who denied that failing to market has affected the country’s tourism elasticity of demand.

\subsection{Contributions on Other Tourism Specific Determinants}

During the research survey, the respondents provided other main determinants which have been regarded as tourism industry specified. These determinants included culture (originality) and environment management (naturalistic). The responses showed that there is a direct relationship between the originality of culture and quantity demanded for tourism products and services. When a tourism destination preserves its culture by maintaining original values, beliefs and norms it becomes unique and will have a price inelastic demand. This means that even if the prices charged in a tourism destination becomes relatively expensive, people will still patronize the tourist destination as it carries a unique culture that everyone want to experience. Therefore in this case culture becomes one of the most dominant determinants of Zimbabwe tourism destination demand. An original culture will lead to a less than proportional decrease in quantity demanded for tourism when the price goes up by a more than proportionate margin. This is in line with the concept of relatively price inelastic.

The current paradigm has seen tourists inclined to environmentally friendly practices. This is because of the increased disturbance in natural resources giving rise to detrimental issues such as global warming and extinction of rare species. The new view has therefore become highly naturalistic with tourists favoring tourism organisations that are practicing green management, eco-certified and sustainable practice endorsed. The response divulged that the new tourist has a relatively high price inelastic demand on tourism products and services 
when a destination is perceived to be purely naturalistic. The construction and establishment of facilities which are aesthetic to nature has increased demand for tourism products and services. Even with a relatively higher pricing system, tourists will always visit an environmental friendly destination as they will manage to see rare species which have become extinct in other tourism destinations. A combination of the two mainly discovered determinants of culture and naturalistic has led to a new tourism elasticity model as shown in figure 2 below.

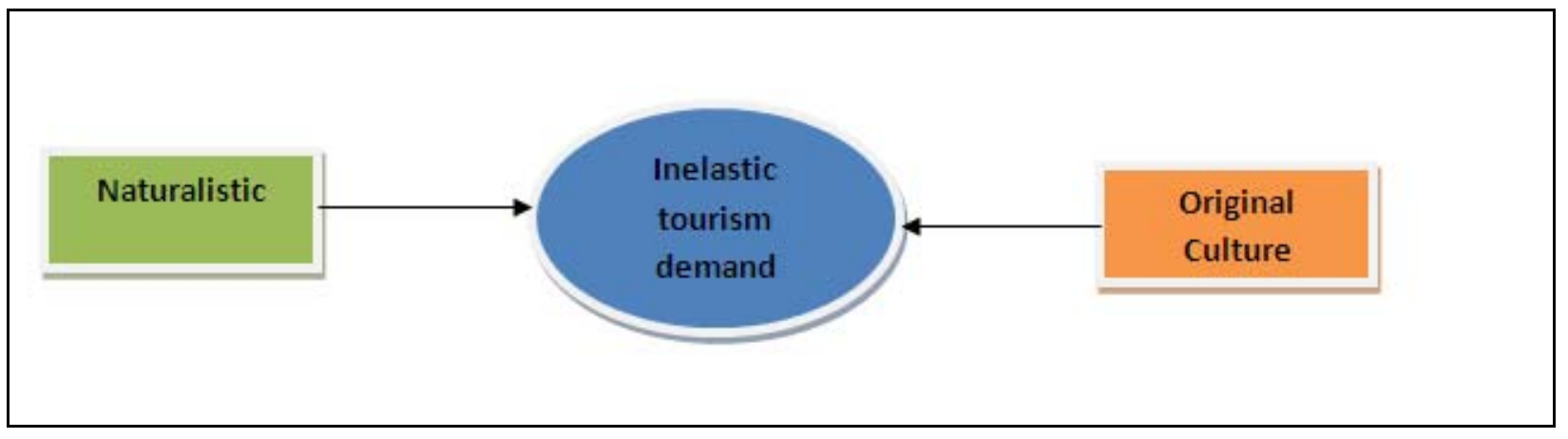

Figure 2. Tourism inelastic demand determinants

Source: Research Design (2015).

\section{Recommendations}

Zimbabwe tourism destination can be effectively positioned through striving to charge low prices. Elasticity of demand avails vital information for tourism organizations and business to manipulate pricing so as to increase demand for tourism products (Tran, 2011). As discovered from the research using the price elasticity of demand concept, the tourism offerings in Zimbabwe are highly perfectly price elastic. This means that a slight increase in the price of the country's offerings will lead to total slump in their demand.

The disposable income of the majority in Zimbabwe is at low levels as it cannot meet the poverty datum level requirements. The tourism income elasticity for various tourism offerings has proven to be negative. This means that the disposable income levels of the locals cannot afford the prices charged by various tourism businesses. Therefore price should be reduced to match with low level of incomes in the economy. This helps in improving the real income of potential local tourists such that they will regard the tourism product as a normal good and increase their consumption.

Zimbabwe tourism destination should charge prices that are relatively cheap compared to other destinations particularly in Africa. The price cross elasticity of demand concept revealed that, Zimbabwe tourism destination prices are relatively high as compared to those of neighbouring destinations. This means that Zimbabwe tourism destination is being substituted with other relatively cheaper destinations thus losing its share on the global 
tourism market. Therefore, to improve on the position of destination Zimbabwe there is a need to adjust the prices so that they become competitive.

Zimbabwe tourist destination should put mechanisms and policies that help in encouraging high preservation of culture and sustainable management of natural resources. This is because, these are the main factors that attract the new type of tourists who is adventurous and expects new experiences associated with originality.

\section{Conclusion}

The concept of elasticity of demand has proven to be an effective tool in positioning Zimbabwe tourism destination. The main discovered elasticity of demand includes price elasticity of demand, income elasticity of demand and cross price elasticity of demand. They measure the responsiveness of quantity demanded for destination tourism offerings due to changes in prices, disposable income and price of other related tourism destinations respectively. Knowledge of these concepts has proven to help in improving tourism destination operators' decision making, destination price strategy, tax decisions of the government and price discrimination.

\section{References}

Chibaya, T. (2013). From 'Zimbabwe Africa's Paradise to Zimbabwe A World of Wonders': Benefits and Challenges of Rebranding Zimbabwe as A Tourist Destination. Developing Country Studies, 13(5), 84-91.

Croes, R., \& Vanegas, M. (2005). An econometric study of tourist arrivals in Aruba and its implications. Tourism Management, 879-890. http://dx.doi.org/10.1016/j.tourman.2004.04.007

Crouch, G. I. (1994a). The Study of International Tourism Demand: A review of findings. Journal of Travel Research, 33, 12-23. http://dx.doi.org/10.1177/004728759403300102

Crouch, G. I. (1996). Demand elasticities in international marketing: A meta-analytical application to tourism. Journal of Business Research, 36, 117-136. http://dx.doi.org/10.1016/0148-2963(95)00086-0

Divisekera, S. (2003). A model of demand for international tourism. Annals of Tourism Research, 30(1), 31-49. http://dx.doi.org/10.1016/S0160-7383(02)00029-4

Lim, C., Min, J., \& McAleer, M. (2008). Modelling income effects on long and short haul international travel from Japan. Tourism Management, 29, 1099-1109. http://dx.doi.org/10.1016/j.tourman.2008.02.012

Lipsey, R. G. (2009). An Introduction to Positive Economics (7th ed.). Oxford: Oxford University Press.

Mankiw, G. N., \& Taylor, M. P. (2006). Economics. London, UK: Thomson Learning.

McConnell, C. R., \& Brue, S. L. (2000). Economics, Principles, Problems and Policies. New York: McGraw Hill. 


\section{Macrothink}

Case Studies in Business and Management

ISSN 2333-3324 2015, Vol. 2, No. 2

Samuelson, P. A., \& Nordhaus, W. D. (2005). Economics (18th ed.). New Delhi: McGraw Hill.

Sloman, J. (2003). Essentials of Economics. London: Prentice Hall.

Song, H., Kim, J., \& Yang, S. (2010). Confidence intervals for tourism demand elasticity. Annals of Tourism Research, 37(2), 377-396. http://dx.doi.org/10.1016/j.annals.2009.10.002

\section{Copyright Disclaimer}

Copyright for this article is retained by the author(s), with first publication rights granted to the journal.

This is an open-access article distributed under the terms and conditions of the Creative Commons Attribution license (http://creativecommons.org/licenses/by/3.0/). 